\title{
Neurological Soft Signs in Patients with Attention Deficit Hyperactivity Disorder Aged 6 to 18 Years Old at a University Hospital: A Cross-sectional Study
}

\author{
Rowena Arca-Cabradilla, MD, \\ Rosalina Q. de Sagun, MD, \\ Maria Antonia Aurora M. Valencia, MD, \\ Michelle Sy, MD
}

\begin{abstract}
Purpose: Attention deficit hyperactivity disorder (ADHD) is a common neurodevelopmental disorder in children persisting into adulthood. Evidence suggests that the condition is etiologically related to delayed brain maturation. The detection of the presence of neurological soft signs can be a means to assess neuromaturation. The objective of this study was to assess the prevalence of neurological soft signs in ADHD patients and determine any correlation between the presence of neurological soft signs with age, gender, severity and type of ADHD which could give further insights into this disorder.
\end{abstract}

Methods: A cross-sectional study was conducted at the Child Neurology and Developmental Pediatrics outpatient clinic which included patients

Rowena Arca-Cabradilla

wencab29@gmail.com

Section of Pediatric Neurology,

Department of Neurology and Psychiatry, Department

of Pediatrics, University of Santo Tomas Hospital
6-18 years old diagnosed with ADHD as well as healthy controls. Patients with other neurodevelopmental conditions (intellectual disability, metabolic disorder, cerebral palsy, abnormal MRI findings), or any condition that may lead to failure to complete the given tasks such as physical handicaps were excluded. Neurological soft signs were measured by utilizing the Physical and Neurological Evaluation for Soft Signs (PANESS) scale.

Key Findings: A total of 48 patients between 6 and 18 years of age (24 ADHD patients and 24 healthy controls) were examined. Neurological soft signs were significantly higher in patients with ADHD and were present regardless of gender, type and severity of ADHD. ADHD patients performed worse on the given tasks as evidenced by higher PANESS scores. There was a weak negative correlation between neurological soft signs and age indicating that soft sign scores decrease with increasing age. There was no statistically significant difference in neurological soft sign scores between those with medication versus without treatment, except for dysrhythmia which was significantly higher in the drug-naive group. 
Significance: Neurological soft signs are common in patients with ADHD and add scientific evidence to the predictive value of neurological soft signs as indicators of the severity of functional impairment in ADHD. The prevalence of neurological soft signs is much higher in children with ADHD than in controls which may have the potential to improve sensitivity in the diagnosis of ADHD.

Keywords: Neurological soft signs, ADHD, PANESS

\section{INTRODUCTION}

Attention deficit hyperactivity disorder (ADHD) is believed to be the most common behavioral disorder in children affecting about $5.2 \%$ of the school-age population globally.[1] The symptoms must be present before 12 years of age and it is characterized by hyperactivity/impulsivity, inattentiveness, or a combination of both. [2] According to the ADHD Society of the Philippines, an estimated $3-5 \%$ of the population aged 0-14 years old are affected with ADHD. [3] In the past 2 years, $6 \%$ of the patients seen at the Developmental Pediatrics Outpatient Clinic of the University of Santo Tomas Hospital have been diagnosed with ADHD. ADHD is not merely a descriptive behavioral disorder but affects areas of the brain subserving important executive functions such as problem solving, planning ahead, understanding others' actions, and impulse control.

Neurological soft signs (NSS) are nonstandard performance on a neurological examination of motor and sensory function in the absence of a focal neurologic deficit. They are grouped into categories comprising of integrative sensory functioning, motor coordination and complex motor sequencing manifesting as poor coordination, speed or accuracy of the limb or axial movements, including those required to maintain balance, dysrhythmias, and overflow are often found during the clinical examination of young children. [4] The links between NSS in children with ADHD and their executive function, symptoms of inattention and hyperactivity-impulsivity remain unclear, but since ADHD is etiologically related to delayed maturation, NSS could be a tool to assess this. The examination for subtle signs, such as the speed of movement, dysrhythmia and overflow with timed movements provides important information that could increase our understanding of the neurobiological bases of ADHD and clinical implications of neurological soft signs. [4]

Children with ADHD have been found to differ significantly in terms of soft signs. Scientific contributions on NSS in ADHD have been reviewed and they support the occurrence of an alteration in the neural networks for motor control inhibition, at the base of the pathophysiology of NSS in children with $A D H D$, as well as a possible central role of dopamine in this neural circuit.[5]

The revised neurological examination for subtle signs [6] is sensitive to soft developmental changes and reveals soft motor deficits in the central nervous system development. Denckla proposed a clear distinction between "soft signs" that, although soft, is abnormal at any age and those that would be normal if found in a younger child. Though it is common to detect soft signs in typically developing younger children, the persistence of soft signs into later childhood and adolescence implies motor dysfunction and could be a marker for atypical neurological development.[7]

In our review of the literature, there are no studies on this subject among Filipino children. This study aimed to assess the presence of neurological soft signs among $A D H D$ patients in comparison with healthy controls, and determine the correlation of NSS with severity and type of ADHD.

This study aimed to compare the prevalence of NSS in ADHD patients and healthy children 6 to 18 years old who were seen at the Child Neurology and Developmental Pediatrics Clinic and to determine the clinical correlates of NSS in patients with ADHD.

\section{METHODOLOGY}

This was a cross-sectional study utilizing a scale conducted among ADHD patients and healthy children from March to October 2018 with a duration of 8 months.

The Physical and Neurological Examination for Soft Signs (PANESS) is a tool used to assess NSS by measuring salient components of motor function, including lateral preference, gait, balance, motor persistence, coordination, overflow, dysrhythmia, and timed movements.

In this Institutional Review Board approved study, purposive sampling was done. All patients diag- 
nosed with ADHD seen at the UST Hospital Child Neurology and Developmental Pediatrics Outpatient Clinic were screened. ADHD criteria based on the Diagnostic and Statistical Manual of Mental Disorders (DSM-5) was reviewed prior to inclusion. Children from the pediatrics outpatient with normal development were included in the healthy control group. The prenatal and birth history, as well as developmental and past medical history, were reviewed. A thorough physical and neurological examination was done. Those excluded from the study were the ones having other neurodevelopmental conditions such as intellectual disability, metabolic disorders, cerebral palsy and those with abnormal neuroimaging findings. Children with a physical handicap as well as those who failed to complete the given tasks were excluded from the study. The principal investigator explained the study and informed consent to the parents and child during the outpatient consultation. Parental consent was then obtained. Verbal assent was obtained for patients who are aged 7 years old and above. For patients 12 to less than 15 years old, the simplified assent form and parental consent were obtained. For patients aged 15 to under 18 years, a cosigned informed consent was obtained with parents. Each patient was provided a copy of the signed informed consent and/or verbal assent. The patients included underwent the examination for NSS using the PANESS scale. The data were then analyzed statistically.

\section{Screening Tool}

The revised PANESS scale consists of 21 items that test lateral preferences, gait and station, and coordination (10 of the items are timed). Items include various walking (on the heels, on the toes, and on the sides of the feet), rapid alternating movements and balancing tasks. PANESS is an observation scale with 21 questions involving gait, laterality, stance, quality of quick movements, impersistence, involuntary movement, speed and symmetry.[7]

\section{PANESS Administration}

With the use of only a stopwatch and record sheet, the PANESS measures key components of motor function which include gait, lateral preference, motor persistence, balance, overflow, dysrhythmia and timed movements. Lateral preference of the hand, foot and eye is assessed by asking the child to demonstrate a variety of lateralized movements. The assessment of gait includes asking the child to ambulate while the balance is measured by making the child stand and then hop on one foot. The assessment of motor persistence and involuntary movements is a 3-part task: 1) standing with feet together and arms outstretched while fingers are spread and eyes closed, 2) standing with eyes closed, mouth open and tongue protruded, and 3) standing tandem. Finger-to-nose task checks motor coordination. The timed movements include three sets of repetitive and three sets of patterned tasks. Patterned actions are alternating patterns of more complex movements performed as quickly as possible. Repetitive motions are simple flexion movements repeated as fast as possible, including hand-patting, finger-tapping and toe-tapping.

\section{PANESS Scoring}

Hand preference is determined based on task performance. The child is right-handed if the right hand was used to perform 9 or more of the 11 tasks. Gait scoring is done by counting the errors. Overflow actions documented during both gait and timed activities signify inefficiency in executing a motor task, and may represent failed inhibition of prepotent movement. The scoring for balance tasks is done by counting the number of hops and the amount of time for standing on each foot. For motor persistence, the amount of time standing with eyes closed is recorded. Choreiform movements are also recorded while doing all stationary tasks. "Axial" scores are the errors observed during gait and station tasks. During timed movements, overflow is categorized by the proximity of extraneous movement to the intended movement. The mirror overflow movements are unintended movements of the homologous muscles of the contralateral extremity. [8]

The scores obtained from each section of the PANESS were expressed as four summary variables: (1) Total Gaits and Stations, (2) Total Overflow, (3) Total Dysrhythmia; and (4) Total Timed Movements.[18]

\section{Sample Size:}

The target minimum sample size of 48 subjects was achieved, with 24 patients each for the control and children with ADHD group based on a level of significance of $5 \%$ and power of $80 \%$. The proportions 
of normal patients expected to have NSS are $50 \%$ (assumed) and $84 \%$ in the control and children with ADHD group, respectively.

Sample size formula: [9]

$$
N \geq \frac{\left[z_{\alpha} \sqrt{P(1-P)\left(\frac{1}{q_{1}}+\frac{1}{q_{2}}\right)+z_{\beta}} \sqrt{\left(\frac{P_{1}\left(1-P_{1}\right)}{q_{1}}\right)+\left(\frac{P_{2}\left(1-P_{2}\right)}{q_{2}}\right)}\right]^{2}}{\left(P_{1}-P_{1}\right)^{2}}
$$

Where:

$q_{1}=$ proportion of subjects in the control group

$q_{2}=$ proportion of subjects in the intervention group

$Z_{\alpha / 2}=$ specified size of the critical region $(5 \%)=$ 1.960

$Z_{\beta / 2}=$ chosen level of power $(80 \%)=0.842$

$\mathrm{P}_{1} / 2$ assumed proportion of subjects with observed NSS in the control group $=50 \%$

$\mathrm{P}_{2}$ = assumed proportion of subjects with observed agitation in the intervention group $=84 \%[2]$

$P \quad=q_{1} P_{1}+q_{2} P_{2}=(0.5)(0.5)+(0.5)(0.84)=$ 0.67

$\mathrm{N}=$ minimum total number of subjects

\section{Statistical Analysis}

Univariate Analysis

Descriptive statistics were used to summarize the general and clinical characteristics of the participants. Frequency and proportion were used for nominal variables, median and range for ordinal variables, and mean and standard deviation for interval/ ratio variables.

\section{Bivariate Analysis}

Independent sample T-test, Mann-Whitney U/ Wilcoxon Sign rank test, and Fisher's Exact/Chisquare test were used to determine the difference of mean, median and frequency between groups, respectively.

\section{Multivariate Analysis}

One-way ANOVA and Kruskal-Wallis tests were used to determine the difference between mean and median of NSS scores.

All valid data shall be included. The missing data shall neither be replaced nor estimated. The null hy- pothesis was rejected at $5 \%$ alpha level of significance. Data analysis was done via STATA 15.

\section{Ethical Considerations}

The study was conducted upon approval by the Institutional Review Board and was preceded by written documentation of informed consent and/or assent. Participation in the study was purely voluntary and without financial compensation.

The interviews were recorded only in writing, and not recorded via video nor audio. The responses and patient information were kept strictly confidential by the primary investigator. A unique alphanumeric code was issued to each patient. The data will be stored in the primary investigator's personal database, which is password-protected and the anticipated duration of storage will be at least five years.

Conflict of Interest: All investigators of this study declare no conflict of interest.

\section{RESULTS}

A total of 48 patients were included in the study for analysis. We evaluated NSS in a total of 48 children, 24 of whom were diagnosed to have ADHD. The average age in the ADHD group was 8 years and $79 \%$ were male. In the healthy control group, the average age was 9 years and $54 \%$ were male (see Table 1). Comparing the ADHD and healthy controls, we had similar characteristics in terms of age, sex and dexterity. There was no significant difference in terms of perinatal and birth events between the ADHD and healthy control groups. In the ADHD group, $70 \%$ were reported to have a family history of ADHD, 75\% currently on medication and $20 \%$ on occupational therapy (see Table 1).

ADHD was furthered classified as type and severity in accordance with the DSM-5 diagnostic criteria. In the 24 children with ADHD, the most common type was the mixed type with $45.83 \%$ and of mild severity comprising $62.5 \%$ (see Table 1.1).

We considered an NSS to be positive if the child scored above zero for that specific item. Across all categories, the children with ADHD had a higher proportion of positive signs except for "dysrhythmia and miscellaneous/involuntary" movements (Table 2).

We also compared actual motor function scores between the two groups. Similar to Table 2, the scores were consistently higher across motor func- 
Patients with ADHD aged 6-18 years seen at the Child neurology and devlopmental pediatrics outpatient clinic of the UST Hospital and healthy control patients seen at the Pediatrics outpatient clinic

Excluded: presence of other neurological condition (intellectual disability, metabolic disorder, cerebral palsy, abnormal MRI findings); failure to complete given tasks; physical handicap

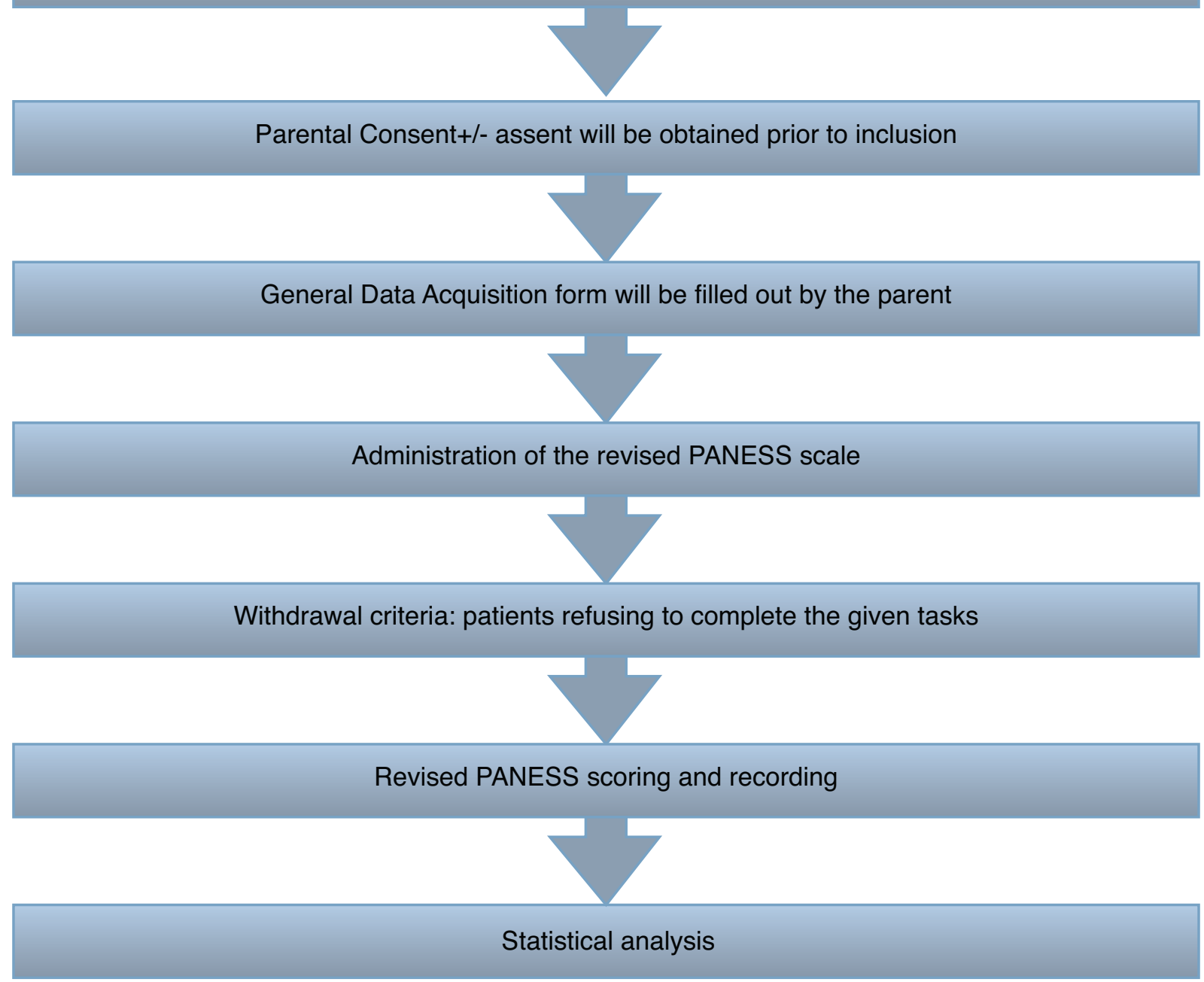

Figure 1. Neurological Soft Signs in ADHD Patients Study Flowchart From Recruitment to Analysis of Data

tion categories in the ADHD group (Table 3). The median PANESS score in the ADHD group was 35, which was significantly higher than that of the control group at 8.5 points $(p<0.001)$.

Among the ADHD patients, the moderate severity ADHD group have higher scores; however, there was no statistically significant difference in scores of NSS between mild and moderate ADHD (see Table 3.1).

We have no statistically significant difference in scores of neurological soft signs between inattentive, impulsive and mixed types except for "miscellaneous/involuntary," where the inattentive type had significantly lower scores compared to impulsive and mixed types (see Table 3.2).

There was no statistically significant difference in NSS scores between those with versus without medication, except for dysrhythmia which was significantly higher in the drug-naïve group (Table 3.3).

There was no statistically significant difference in NSS scores between those with versus without occupational therapy (Table 3.4). 
Table 1. Comparison between ADHD and control groups as to age, gender and clinical history $(n=28)$

\begin{tabular}{|c|c|c|c|c|}
\hline & $\begin{array}{c}\text { Total } \\
(\mathrm{n}=48)\end{array}$ & $\begin{array}{l}\text { Control } \\
(n=24)\end{array}$ & $\begin{array}{l}\text { ADHD } \\
(n=24)\end{array}$ & p-value \\
\hline \multicolumn{5}{|c|}{ Mean \pm SD; Frequency (\%); Median (Range) } \\
\hline Age & $9(6-19)$ & $9(6-18)$ & $8(6-19)$ & $0.211^{*}$ \\
\hline Sex & & & & $0.066^{\dagger}$ \\
\hline Male & $32(66.67)$ & $13(54.17)$ & $19(79.17)$ & \\
\hline Female & $16(33.33)$ & $11(45.83)$ & $5(20.83)$ & \\
\hline Dexterity & & & & $0.318^{\ddagger}$ \\
\hline Left & $12(25)$ & $8(33.33)$ & 4 (16.67) & \\
\hline Right & $36(75)$ & $16(66.67)$ & $20(83.33)$ & \\
\hline $\begin{array}{l}\text { Pertinent prenatal } \\
\text { history }\end{array}$ & & & & $1.000^{\ddagger}$ \\
\hline Term & $46(95.83)$ & $23(95.83)$ & $23(95.83)$ & \\
\hline Pre-term & $2(4.17)$ & $1(4.17)$ & $1(4.17)$ & \\
\hline Birth history & & & & $0.330^{\dagger}$ \\
\hline CS & $13(27.08)$ & $5(20.83)$ & $8(33.33)$ & \\
\hline NSD & $35(72.92)$ & $19(79.17)$ & $16(66.67)$ & \\
\hline \multicolumn{5}{|l|}{ Family history } \\
\hline Intellectual disability & $10(20.83)$ & $8(33.33)$ & $2(8.33)$ & $0.072^{\ddagger}$ \\
\hline ADHD & $17(35.42)$ & 0 & $17(70.83)$ & $<0.001^{\ddagger}$ \\
\hline Under medication & $18(37.5)$ & 0 & 18 (75) & $<0.001^{\ddagger}$ \\
\hline Occupational therapy & $5(10.42)$ & 0 & $5(20.83)$ & $0.05^{\ddagger}$ \\
\hline
\end{tabular}

Statistical tests used: * - Wilcoxon rank sum test; $\dagger$ - Chi-square test; $¥$ - Fisher's exact test

Table 1.1. ADHD distribution as to type and severity $(n=24)$

\begin{tabular}{lc}
\hline & Frequency $(\%)$ \\
\hline Type & $5(20.83)$ \\
Inattentive & $8(33.33)$ \\
Impulsive & $11(45.83)$ \\
Mixed & \\
Severity & $15(62.5)$ \\
Mild & $9(37.5)$ \\
Moderate & 0 \\
Severe &
\end{tabular}

Overall, there is a weak negative correlation between NSS and age. This indicates that soft sign scores decrease with increasing age. In the ADHD group, weak to moderate negative correlation was statistically significant in the overflow movements and slow for age scores. In the control group, we also noted a weak and negative correlation between age and NSS for overflow and dysrhythmia scores (see Table 4).

We had insufficient evidence to demonstrate a difference in overflow scores between males and females (see Table 5).

\section{DISCUSSION}

Attention deficit hyperactivity disorder (ADHD) is a disorder that manifests in childhood and may persist into adulthood with symptoms of hyperactivity, impulsivity, and/or inattention.[10] Besides the "core" symptoms, the motor ability of ADHD children is often significantly poorer than it should be based on their age and level of intellectual functioning.[4] Several papers have already documented the presence of these soft signs, nonetheless, this study delved further on correlating PANESS scores with type and severity of $A D H D$. Attention was also given in investigating whether these scores could be a means to monitor the response to treatment. NSS is used as a screening tool for psychopathology and diagnosis of ADHD. [11] In the past, several standardized neurological test instruments in research and clinical practice have been used to identify and quantify NSS. One of the first was PANESS[12]. In clinical practice, the revised neurological examination for subtle signs is sensitive to soft developmental changes and reveals soft motor deficits in the central nervous system development.[6] 
Table 2. Comparison of prevalence of neurological soft signs in ADHD and healthy children as to gait/station and timed movement tasks $(n=28)$

\begin{tabular}{|c|c|c|c|c|}
\hline & $\begin{array}{c}\text { Total } \\
(n=48)\end{array}$ & $\begin{array}{l}\text { Control } \\
(n=24)\end{array}$ & $\begin{array}{l}\text { ADHD } \\
(n=24)\end{array}$ & p-value \\
\hline \multicolumn{5}{|c|}{ Frequency (\%) } \\
\hline \multicolumn{5}{|l|}{ Gaits and Stations } \\
\hline Axial & $24(50)$ & $3(12.5)$ & $21(87.5)$ & $<0.001^{\ddagger}$ \\
\hline Right & $17(35.42)$ & $2(8.33)$ & $15(62.5)$ & $<0.001^{\ddagger}$ \\
\hline Left & $19(39.58)$ & $2(8.33)$ & $17(70.83)$ & $<0.001^{\ddagger}$ \\
\hline Overflow & $19(39.58)$ & $1(4.17)$ & $18(75)$ & $<0.001^{\ddagger}$ \\
\hline Right & 19 (39.58) & $1(4.17)$ & $18(75)$ & $<0.001^{\ddagger}$ \\
\hline Left & $19(39.58)$ & $1(4.17)$ & $18(75)$ & $<0.001^{\ddagger}$ \\
\hline Miscellaneous/Involuntary & $39(81.25)$ & $16(66.67)$ & $23(95.83)$ & $0.023^{\ddagger}$ \\
\hline Right & $33(68.75)$ & $11(45.83)$ & $22(91.67)$ & $0.001^{\ddagger}$ \\
\hline Left & $33(68.75)$ & $11(45.83)$ & $22(91.67)$ & $0.001^{\ddagger}$ \\
\hline \multicolumn{5}{|l|}{ Timed movements } \\
\hline Overflow & $32(66.67)$ & $11(45.83)$ & $21(87.5)$ & $0.005^{\ddagger}$ \\
\hline Right & $27(56.25)$ & $6(25)$ & $21(87.5)$ & $<0.001^{\ddagger}$ \\
\hline Left & $27(56.25)$ & $6(25)$ & $21(87.5)$ & $<0.001^{\ddagger}$ \\
\hline Dysrhythmia & $41(85.42)$ & $18(75)$ & $23(95.3)$ & $0.097^{\ddagger}$ \\
\hline Right & $33(68.75)$ & $13(54.17)$ & $20(83.33)$ & $0.06^{\ddagger}$ \\
\hline Left & $36(75)$ & $16(66.67)$ & $20(83.33)$ & $0.318^{\ddagger}$ \\
\hline Miscellaneous/Involuntary & $4(8.33)$ & 0 & $4(16.67)$ & $0.109^{\ddagger}$ \\
\hline Right & $4(8.33)$ & 0 & 4 (16.67) & $0.109^{\ddagger}$ \\
\hline Left & $3(6.25)$ & 0 & $3(12.5)$ & $0.234^{\ddagger}$ \\
\hline SFA & 41 (85.42) & $17(70.83)$ & $24(100)$ & $0.009^{\ddagger}$ \\
\hline Right & $36(75)$ & $13(54.17)$ & $23(95.83)$ & $0.002^{\ddagger}$ \\
\hline Left & $36(75)$ & 13 (54.17) & 23 (95.83) & $0.002^{\ddagger}$ \\
\hline
\end{tabular}

SFA - Slow for age

The following points were identified in our results: 1) across all categories, ADHD patients had a significantly higher proportion of positive soft signs except for miscellaneous/involuntary movements. 2) The PANESS scores in ADHD patients were significantly higher as compared to normally developing children. 3) There was no significant difference in terms of NSS among the inattentive, impulsive and mixed ADHD types except for the miscellaneous/involuntary where the inattentive type had significantly lower scores. 4) There was no significant difference in the scores of NSS in terms of gender, severity and treatment of ADHD (except for dysrhythmia which was significantly higher in the drug-naive group). 5) NSS scores decrease with increasing age.

To better understand the role of motor disorders in the gamut of manifestations of ADHD, we assess the specific areas of the nervous system involved in the production of movement. The main roles of the frontal lobe are superior executive function, emotional regulation and movement control.[13] Planning of complex behaviors is subserved by the prefrontal cortex, which then produces the complex sequences of movement suitable for the task, and the primary motor cortex is responsible for executing skilled movements. All these areas are connected to diverse subcortical structures forming subcortical circuits.[13]

In addition to the prefrontal cortex, there is also the involvement of the basal ganglia and the cerebellum as evidenced by magnetic resonance studies. $[14,15]$ It has been proposed in neuropsychologic testing that patients with ADHD have impaired executive functions and/or difficulties with response inhibition. $[17,18]$ These excessive movements seem to reflect the immaturity of the neural networks involved in inhibitory control.[16] 
Table 3. Comparison of PANESS scores in children with ADHD vs normal developing children using gait/station and timed movement tasks

\begin{tabular}{|c|c|c|c|c|}
\hline & $\begin{array}{c}\text { Total } \\
(n=48)\end{array}$ & $\begin{array}{l}\text { Control } \\
(n=24)\end{array}$ & $\begin{array}{l}\text { ADHD } \\
(n=24)\end{array}$ & p-value \\
\hline \multicolumn{5}{|c|}{ Mean \pm SD; Median (Range) } \\
\hline Gaits and Stations & $3.5(0-29)$ & $2(0-8)$ & $14.5(0-29)$ & $<0.001^{*}$ \\
\hline Axial & $0.5(0-16)$ & $0(0-4)$ & $3.5(0-16)$ & $<0.001^{*}$ \\
\hline Right & $0(0-8)$ & $0(0-2)$ & $1(0-8)$ & $<0.001^{*}$ \\
\hline Left & $0(0-8)$ & $0(0-2)$ & $1(0-8)$ & $<0.001^{*}$ \\
\hline Overflow & $0(0-6)$ & $0(0-2)$ & $4(0-6)$ & $<0.001^{*}$ \\
\hline Right & $0(0-3)$ & $0(0-1)$ & $2(0-3)$ & $<0.001^{*}$ \\
\hline Left & $0(0-3)$ & $0(0-1)$ & $2(0-3)$ & $<0.001^{*}$ \\
\hline Miscellaneous/Involuntary & $3.67 \pm 2.88$ & $1.54 \pm 1.44$ & $5.79 \pm 2.32$ & $<0.001^{\S}$ \\
\hline Right & $1.48 \pm 1.34$ & $0.5 \pm 0.59$ & $2.46 \pm 1.14$ & $<0.001^{\S}$ \\
\hline Left & $1.48 \pm 1.34$ & $0.5 \pm 0.59$ & $2.46 \pm 1.14$ & $<0.001^{\S}$ \\
\hline Timed movements & $13(1-45)$ & $7(1-19)$ & $21(8-45)$ & $<0.001^{*}$ \\
\hline Overflow & $2.5(0-16)$ & $0(0-8)$ & $5.5(0-16)$ & $<0.001 *$ \\
\hline Right & $1(0-8)$ & $0(0-4)$ & $3(0-8)$ & $<0.001 *$ \\
\hline Left & $1(0-7)$ & $0(0-4)$ & $3(0-7)$ & $<0.001^{*}$ \\
\hline Dysrhythmia & $3(0-11)$ & $2(0-6)$ & $3.5(0-11)$ & $0.009^{*}$ \\
\hline Right & $1(0-5)$ & $1(0-3)$ & $2(0-5)$ & $0.014^{*}$ \\
\hline Left & $1.44 \pm 1.13$ & $1 \pm 0.83$ & $1.88 \pm 1.23$ & $0.006^{\S}$ \\
\hline Miscellaneous/Involuntary & $0.17 \pm 0.56$ & 0 & $0.33 \pm 0.76$ & $0.037^{\S}$ \\
\hline Right & $0(0-2)$ & $0(0-0)$ & $0(0-2)$ & $0.043^{*}$ \\
\hline Left & $0(0-1)$ & $0(0-0)$ & $0(0-1)$ & $0.077^{*}$ \\
\hline SFA & $6.5(0-26)$ & $3.5(0-18)$ & $11.5(2-26)$ & $<0.001^{*}$ \\
\hline Right & $3.5(0-12)$ & $1(0-8)$ & $6(0-12)$ & $<0.001^{*}$ \\
\hline Left & $2(0-12)$ & $1(0-8)$ & $4.5(0-12)$ & $<0.001^{*}$ \\
\hline Total Right Overflow & $1.5(0-10)$ & $0(0-4)$ & $5.5(0-10)$ & $<0.001^{*}$ \\
\hline Total Left Overflow & $1.5(0-10)$ & $0(0-4)$ & $5.5(0-10)$ & $<0.001^{*}$ \\
\hline Total Overall Overflow & $3.5(0-20)$ & $0(0-8)$ & $11.5(0-20)$ & $<0.001^{*}$ \\
\hline PANESS Total & $20(1-67)$ & $8.5(1-20)$ & $35(18-67)$ & $<0.001 *$ \\
\hline
\end{tabular}

Statistical tests used: * - Wilcoxon rank-sum test; $\S$ - Independent sample T-test

SFA - Slow for age

\section{Neurological Soft Signs in ADHD}

As hypothesized, our present study significantly revealed the presence of NSS in the ADHD group as compared to the healthy controls. Patients with ADHD showed multiple motor abnormalities as compared to the control group in terms of overflow movements, imbalance and greater motor slowness as exhibited by higher slow for age (SFA) scores. All ADHD patients significantly performed worse on the PANESS scale as demonstrated by higher PANESS scores. These findings are consistent with the results of previous studies that emphasized motor dysfunction in ADHD patients. Pitzianti, et al. evaluated the attention and motor functioning of $27 \mathrm{ADHD}$ patients. The results showed that ADHD patients had impairments in motor function.[31] In a cross-sectional study by Patankar in 2012, NSS was found in $84 \%$ of the 52 Indian children diagnosed with ADHD.[9] Previous studies in congruence with our findings include those done by Uslu [19], Meyer and Sagvolden [20] and Pitcher in 2003.[21] The higher prevalence of NSS in ADHD can be explained by a reduction in the size of the inferior frontal gyrus, middle and superior temporal gyrus, and anterior cingulate gyrus. [22] Prefrontal striatal circuits underpin the executive function and dysfunction and have 
Table 3.1 Correlation of neurological soft sign scores with the severity of ADHD ( $n=24)$

\begin{tabular}{|c|c|c|c|c|}
\hline & $\begin{array}{c}\text { Total } \\
(n=24)\end{array}$ & $\begin{array}{c}\text { Mild } \\
(n=15)\end{array}$ & $\begin{array}{c}\text { Moderate } \\
(\mathrm{n}=9)\end{array}$ & p-value \\
\hline \multicolumn{5}{|c|}{ Mean \pm SD; Median (Range) } \\
\hline Gaits and Stations & $14.04 \pm 7.17$ & $13.47 \pm 8.13$ & $15 \pm 5.5$ & $0.623^{\S}$ \\
\hline Axial & $3.5(0-16)$ & $3(0-16)$ & $4(0-9)$ & $0.764^{*}$ \\
\hline Right & $1(0-8)$ & $1(0-8)$ & $2(0-4)$ & $0.174^{*}$ \\
\hline Left & $1(0-8)$ & $1(0-8)$ & $1(0-4)$ & $0.561 *$ \\
\hline Overflow & $3.67 \pm 2.55$ & $3.2 \pm 2.48$ & $4.44 \pm 2.6$ & $0.256^{\S}$ \\
\hline Right & $1.83 \pm 1.27$ & $1.6 \pm 1.24$ & $2.22 \pm 1.3$ & $0.256^{\S}$ \\
\hline Left & $1.83 \pm 1.27$ & $1.6 \pm 1.24$ & $2.22 \pm 1.3$ & $0.256^{\S}$ \\
\hline $\begin{array}{l}\text { Miscellaneous/ } \\
\text { Involuntary }\end{array}$ & $5.79 \pm 2.32$ & $5.47 \pm 2.59$ & $6.33 \pm 1.8$ & $0.388^{\S}$ \\
\hline Right & $2.46 \pm 1.14$ & $2.27 \pm 1.22$ & $2.78 \pm 0.97$ & $0.298^{8}$ \\
\hline Left & $2.46 \pm 1.14$ & $2.27 \pm 1.22$ & $2.78 \pm 0.97$ & $0.298^{\S}$ \\
\hline Timed movements & $23.79 \pm 10$ & $22.27 \pm 9.61$ & $26.33 \pm 10.68$ & $0.346^{\S}$ \\
\hline Overflow & $7.33 \pm 5$ & $6.2 \pm 4.83$ & $9.22 \pm 4.97$ & $0.156^{\S}$ \\
\hline Right & $3.54 \pm 2.43$ & $2.87 \pm 2.2$ & $4.67 \pm 2.5$ & $0.079 \S$ \\
\hline Left & $3(0-7)$ & $2(0-7)$ & $5(1-7)$ & $0.276^{*}$ \\
\hline Dysrhythmia & $3.79 \pm 2.3$ & $3.27 \pm 2.71$ & $4.67 \pm 1$ & $0.153^{\S}$ \\
\hline Right & $1.63 \pm 1.17$ & $1.4 \pm 1.35$ & $2 \pm 0.71$ & $0.233^{\S}$ \\
\hline Left & $1.88 \pm 1.23$ & $1.53 \pm 1.36$ & $2.44 \pm 0.73$ & $0.078^{\S}$ \\
\hline $\begin{array}{l}\text { Miscellaneous/ } \\
\text { Involuntary }\end{array}$ & $0.33 \pm 0.76$ & $0.27 \pm 0.7$ & $0.44 \pm 0.88$ & $0.591^{\S}$ \\
\hline Right & $0(0-2)$ & $0(0-2)$ & $0(0-1)$ & $0.646^{*}$ \\
\hline Left & $0(0-1)$ & $0(0-1)$ & $0(0-1)$ & $0.275^{*}$ \\
\hline SFA & $12.33 \pm 6.91$ & $12.53 \pm 7.39$ & $12 \pm 6.44$ & $0.859^{\S}$ \\
\hline Right & $5.79 \pm 3.22$ & $5.93 \pm 3.33$ & $5.56 \pm 3.21$ & $0.787^{\S}$ \\
\hline Left & $5.29 \pm 3.41$ & $5.53 \pm 3.56$ & $4.89 \pm 3.3$ & $0.664^{\S}$ \\
\hline Total Right Overflow & $5.38 \pm 3.09$ & $4.47 \pm 3.16$ & $6.89 \pm 2.42$ & $0.061^{\S}$ \\
\hline Total Left Overflow & $5.21 \pm 3.23$ & $4.6 \pm 3.42$ & $6.22 \pm 2.77$ & $0.242^{\S}$ \\
\hline Total Overall Overflow & $11 \pm 6.44$ & $9.4 \pm 6.73$ & $13.67 \pm 5.22$ & $0.118^{\S}$ \\
\hline PANESS Total & $37.83 \pm 13.78$ & $35.73 \pm 15.06$ & $41.33 \pm 11.28$ & $0.347^{\S}$ \\
\hline
\end{tabular}

Statistical tests used: * - Wilcoxon rank-sum test; $\S$ - Independent sample T-test SFA - Slow for age

long been considered an important neuropsychological correlate of ADHD.[15] The current findings in our study are speculated to be a manifestation of the "prefrontal-striatal" model of ADHD.

\section{Clinical Correlates of NSS in ADHD}

In our study, there is a weak negative correlation between NSS and age, indicating that soft sign scores decrease with increasing age. This was consistent with the results obtained by Azza [23] and Dickstein [5], who found that older patients performed better on the NSS scale. This can be explicated by the hormonal events of puberty exerting profound effects on brain maturation and behavior.[24] More importantly, a decrease in soft signs with age is due to the integration of higher-order processes such as attention with a lower-level neuromotor inhibitory mechanism. [25] This is contrary to the study done by HaddersAlgra wherein NSS was shown to be low in the preschool age and that there was a steady increase in the frequency of soft signs.[26]

Gender differences in NSS were insignificant in our study fitting with that of the study done by Gustafsson, 
Table 3.2 Correlation of neurological soft sign scores with the different types of ADHD ( $n=24)$

\begin{tabular}{|c|c|c|c|c|}
\hline & $\begin{array}{c}\text { Inattentive } \\
(n=5)\end{array}$ & $\begin{array}{c}\text { Impulsive- } \\
\text { Hyperactive } \\
(\mathbf{n}=8)\end{array}$ & $\begin{array}{l}\text { Mixed type } \\
\quad(n=11)\end{array}$ & p-value \\
\hline \multicolumn{5}{|c|}{ Mean \pm SD; Median (Range) } \\
\hline Gaits and Stations & $9.6 \pm 10.11$ & $17.63 \pm 6.82$ & $13.45 \pm 4.91$ & $0.135^{\prime \prime}$ \\
\hline Axial & $1(0-16)$ & $5.5(2-16)$ & $4(0-8)$ & $0.183^{\pi}$ \\
\hline Right & $0(0-8)$ & $1(0-8)$ & $2(0-3)$ & $0.277 \pi$ \\
\hline Left & $1(0-8)$ & $2(0-5)$ & $1(0-3)$ & $0.333^{\pi}$ \\
\hline Overflow & $2.4 \pm 2.61$ & $4.75 \pm 2.12$ & $3.45 \pm 2.7$ & $0.262^{\prime \prime}$ \\
\hline Right & $1.2 \pm 1.3$ & $2.38 \pm 1.06$ & $1.73 \pm 1.35$ & $0.262^{\prime \prime}$ \\
\hline Left & $1.2 \pm 1.3$ & $2.38 \pm 1.06$ & $1.73 \pm 1.35$ & $0.262^{\prime \prime}$ \\
\hline Miscellaneous/Involuntary & $3.2 \pm 2.86$ & $6.5 \pm 1.41$ & $6.45 \pm 1.86$ & $0.012^{\prime \prime}$ \\
\hline Right & $1.2 \pm 1.3$ & $2.75 \pm 0.71$ & $2.82 \pm 0.98$ & $0.014^{\prime \prime}$ \\
\hline Left & $1.2 \pm 1.3$ & $2.75 \pm 0.71$ & $2.82 \pm 0.98$ & $0.014^{\prime \prime}$ \\
\hline Timed movements & $24.2 \pm 8.23$ & $20 \pm 10.16$ & $26.36 \pm 10.57$ & $0.407 \|$ \\
\hline Overflow & $4.2 \pm 3.19$ & $7.88 \pm 4.7$ & $8.36 \pm 5.63$ & $0.295^{\prime \prime}$ \\
\hline Right & $2 \pm 1.41$ & $3.63 \pm 2.26$ & $4.18 \pm 2.75$ & $0.258^{\prime \prime}$ \\
\hline Left & $2(0-4)$ & $4.5(0-7)$ & $5(0-7)$ & 0.350 \\
\hline Dysrhythmia & $2.8 \pm 2.68$ & $3.5 \pm 3.21$ & $4.45 \pm 1.04$ & $0.391^{11}$ \\
\hline Right & $1.2 \pm 1.3$ & $1.38 \pm 1.6$ & $2 \pm 0.63$ & $0.358^{\prime \prime}$ \\
\hline Left & $1.2 \pm 1.3$ & $1.88 \pm 1.46$ & $2.18 \pm 0.98$ & $0.348^{\prime \prime}$ \\
\hline Miscellaneous/Involuntary & $0 \pm 0$ & $0.5 \pm 0.93$ & $0.36 \pm 0.81$ & $0.528 "$ \\
\hline Right & $0(0-0)$ & $0(0-2)$ & $0(0-1)$ & $0.487^{\pi}$ \\
\hline Left & $0(0-0)$ & $0(0-1)$ & $0(0-1)$ & $0.608 \pi$ \\
\hline SFA & $17.2 \pm 5.4$ & $8.13 \pm 5.54$ & $13.18 \pm 7.05$ & $0.053^{\prime \prime}$ \\
\hline Right & $7.8 \pm 2.49$ & $4.13 \pm 2.95$ & $6.09 \pm 3.3$ & $0.121^{11}$ \\
\hline Left & $7.8 \pm 3.03$ & $3.25 \pm 2.43$ & $5.64 \pm 3.5$ & $0.05^{\prime \prime}$ \\
\hline Total Right Overflow & $3.2 \pm 2.59$ & $6 \pm 2.93$ & $5.91 \pm 3.21$ & $0.215^{\prime \prime}$ \\
\hline Total Left Overflow & $3 \pm 2.55$ & $6.25 \pm 3.2$ & $5.45 \pm 3.3$ & $0.204^{\prime \prime}$ \\
\hline Total Overall Overflow & $6.6 \pm 5.55$ & $12.63 \pm 6.09$ & $11.82 \pm 6.68$ & $0.228^{\prime \prime}$ \\
\hline PANESS Total & $33.8 \pm 17.75$ & $37.63 \pm 14.71$ & $39.82 \pm 12.12$ & $0.737^{\prime \prime}$ \\
\hline
\end{tabular}

Statistical tests used: II - One way ANOVA; I - Kruskal Wallis test SFA - Slow for age

which showed higher scores in the male population but was not statistically significant.[27] Interestingly, in the study by Larson and colleagues, there was a gender difference for timed patterned movements, but not for timed repetitive movements suggestive of the fact that the neural pathways and motor systems underlying patterned movement may mature differently in females than in males.[32]

NSS was not significantly correlated with the type of ADHD except for the inattentive type which had significantly lower scores in terms of involuntary movements. Very few studies have focused on correlations between the types of ADHD and soft signs.
This finding is similar to one study wherein children with inattentive type ADHD had significantly poorer fine motor skills, while children with combined-type ADHD were found to experience significantly greater difficulties with gross motor skills.[28] A study done by Patankar revealed that the inattentive type had significant overflow movements which are indicative of delayed motor inhibition.[9]

There was no statistically significant difference in the scores of NSS between mild and moderate ADHD in our study in contrast to Patankar, et al. [9] wherein significant scores were higher in more severe ADHD. When compared to normal children, 
Table 3.3 Correlation of neurological soft sign scores as to ADHD pharmacotherapy $(n=24)$

\begin{tabular}{|c|c|c|c|}
\hline & $\begin{array}{l}\text { With medication } \\
(n=18)\end{array}$ & $\begin{array}{l}\text { Without medication } \\
\qquad(n=6)\end{array}$ & p-value \\
\hline \multicolumn{4}{|c|}{ Mean \pm SD; Median (Range) } \\
\hline Gaits and Stations & $13 \pm 7.43$ & $17.17 \pm 5.74$ & $0.225^{\S}$ \\
\hline Axial & $3(0-16)$ & $4.5(1-16)$ & $0.401 *$ \\
\hline Right & $1(0-8)$ & $1.5(0-8)$ & $0.863^{*}$ \\
\hline Left & $1(0-5)$ & $1.5(0-8)$ & $0.393^{*}$ \\
\hline Overflow & $3.22 \pm 2.67$ & $5 \pm 1.67$ & $0.142^{\S}$ \\
\hline Right & $1.61 \pm 1.33$ & $2.5 \pm 0.84$ & $0.142^{\S}$ \\
\hline Left & $1.61 \pm 1.33$ & $2.5 \pm 0.84$ & $0.142^{\S}$ \\
\hline Miscellaneous/Involuntary & $5.67 \pm 2.45$ & $6.17 \pm 2.04$ & $0.658^{\S}$ \\
\hline Right & $2.39 \pm 1.2$ & $2.67 \pm 1.03$ & $0.617^{\S}$ \\
\hline Left & $2.39 \pm 1.2$ & $2.67 \pm 1.03$ & $0.617^{\S}$ \\
\hline Timed movements & $24.28 \pm 9.6$ & $22.33 \pm 11.94$ & $0.689^{\S}$ \\
\hline Overflow & $7.78 \pm 5.11$ & $6 \pm 4.86$ & $0.463^{\S}$ \\
\hline Right & $3.78 \pm 2.56$ & $2.83 \pm 2.04$ & $0.422^{\S}$ \\
\hline Left & $4.5(0-7)$ & $1.5(0-7)$ & $0.361 *$ \\
\hline Dysrhythmia & $3.22 \pm 1.73$ & $5.5 \pm 3.08$ & $0.033^{\S}$ \\
\hline Right & $1.39 \pm 0.98$ & $2.33 \pm 1.51$ & $0.088^{\S}$ \\
\hline Left & $1.56 \pm 1.1$ & $2.83 \pm 1.17$ & $0.024^{\S}$ \\
\hline Miscellaneous/Involuntary & $0(0-2)$ & $0(0-2)$ & $1.000^{*}$ \\
\hline Right & $0(0-2)$ & $0(0-1)$ & $0.959^{*}$ \\
\hline Left & $0(0-1)$ & $0(0-1)$ & $0.727^{*}$ \\
\hline SFA & $12.94 \pm 6.34$ & $10.5 \pm 8.8$ & $0.465^{\S}$ \\
\hline Right & $5.94 \pm 3.15$ & $5.33 \pm 3.67$ & $0.696^{\S}$ \\
\hline Left & $5.56 \pm 2.94$ & $4.5 \pm 4.81$ & $0.523^{\S}$ \\
\hline Total Right Overflow & $5.39 \pm 3.27$ & $5.33 \pm 2.73$ & $0.971^{\S}$ \\
\hline Total Left Overflow & $5.28 \pm 3.34$ & $5 \pm 3.16$ & $0.890^{\S}$ \\
\hline Total Overall Overflow & $11 \pm 6.71$ & $11 \pm 6.13$ & $1.000^{\S}$ \\
\hline PANESS Total & $37.28 \pm 13.8$ & $39.5 \pm 14.88$ & $0.741^{\S}$ \\
\hline
\end{tabular}

Statistical tests used: * - Wilcoxon rank-sum test; $\S$ - Independent sample T-test

SFA - Slow for age

ADHD children significantly differ with respect to soft signs; the more severe the ADHD, the greater are the soft signs. There is a certain correlation of NSS with neurodevelopmental disorders such as ADHD. [29] There were no severe ADHD subjects enrolled in our study, but looking at the results, the moderate group showed higher scores though not statistically significant and could be due to a low sample size.

There was no statistically significant difference in NSS scores between those with versus without methylphenidate medication, except for dysrhythmia which was significantly higher in the untreated group. Likewise, there was no significant difference in NSS scores between those undergoing occupational therapy and those who are not. This is somehow consistent with the results of the study by Rubia, et al. who demonstrated the effectiveness of methylphenidate on deficits in motor timing in ADHD children and extended its use from the domain of attention and inhibitory functions to the domain of executive motor timing. [30] This is different from the study done by Azza and colleagues wherein NSS was not correlated with medical interventions.[23] All errors in particular items of the NSS examination are related to planning and controlling the action. The motor planning is related to the pre-supplemen- 
Table 3.4 Correlation of neurological soft sign scores as to occupational therapy $(n=24)$

\begin{tabular}{|c|c|c|c|}
\hline & $\begin{array}{l}\text { With occupational } \\
\text { therapy }(n=5)\end{array}$ & $\begin{array}{l}\text { Without occupational } \\
\text { therapy }(n=19)\end{array}$ & p-value \\
\hline \multicolumn{4}{|c|}{ Mean \pm SD; Median (Range) } \\
\hline Gaits and Stations & $11.8 \pm 4.92$ & $14.63 \pm 7.65$ & $0.444^{\S}$ \\
\hline Axial & $3(0-8)$ & $4(0-16)$ & $0.519^{*}$ \\
\hline Right & $2(0-3)$ & $1(0-8)$ & $0.854^{*}$ \\
\hline Left & $1(0-3)$ & $1(0-8)$ & $0.560^{*}$ \\
\hline Overflow & $2.8 \pm 2.28$ & $3.89 \pm 2.62$ & $0.405^{\S}$ \\
\hline Right & $1.4 \pm 1.14$ & $1.95 \pm 1.31$ & $0.405^{\S}$ \\
\hline Left & $1.4 \pm 1.14$ & $1.95 \pm 1.31$ & $0.405^{\S}$ \\
\hline Miscellaneous/Involuntary & $6.2 \pm 2.28$ & $5.68 \pm 2.38$ & $0.668^{\S}$ \\
\hline Right & $2.6 \pm 1.14$ & $2.42 \pm 1.17$ & $0.763^{\S}$ \\
\hline Left & $2.6 \pm 1.14$ & $2.42 \pm 1.17$ & $0.763^{\S}$ \\
\hline Timed movements & $24.8 \pm 10.89$ & $23.53 \pm 10.05$ & $0.806^{\S}$ \\
\hline Overflow & $8.8 \pm 6.57$ & $6.95 \pm 4.65$ & $0.473^{\S}$ \\
\hline Right & $4.4 \pm 3.05$ & $3.32 \pm 2.29$ & $0.387^{\S}$ \\
\hline Left & $6(0-7)$ & $2(0-7)$ & $0.563^{*}$ \\
\hline Dysrhythmia & $4.4 \pm 1.14$ & $3.63 \pm 2.52$ & $0.519^{\S}$ \\
\hline Right & $1.8 \pm 0.84$ & $1.58 \pm 1.26$ & $0.716^{\S}$ \\
\hline Left & $2.6 \pm 0.55$ & $1.68 \pm 1.29$ & $0.141^{\S}$ \\
\hline Miscellaneous/Involuntary & $0(0-2)$ & $0(0-2)$ & $0.826^{*}$ \\
\hline Right & $0(0-1)$ & $0(0-2)$ & $0.869 *$ \\
\hline Left & $0(0-1)$ & $0(0-1)$ & $0.577^{*}$ \\
\hline SFA & $11.2 \pm 5.26$ & $12.63 \pm 7.37$ & $0.690^{\S}$ \\
\hline Right & $5.6 \pm 2.51$ & $5.84 \pm 3.44$ & $0.885^{\S}$ \\
\hline Left & $4.8 \pm 2.17$ & $5.42 \pm 3.7$ & $0.725^{\S}$ \\
\hline Total Right Overflow & $5.8 \pm 3.83$ & $5.26 \pm 2.98$ & $0.738^{\S}$ \\
\hline Total Left Overflow & $5.4 \pm 4.1$ & $5.16 \pm 3.1$ & $0.885^{\S}$ \\
\hline Total Overall Overflow & $11.6 \pm 8.17$ & $10.84 \pm 6.17$ & $0.821^{\S}$ \\
\hline PANESS Total & $36.6 \pm 13.41$ & $38.16 \pm 14.22$ & $0.828^{\S}$ \\
\hline
\end{tabular}

Statistical tests used: * - Wilcoxon rank-sum test; $\S$ - Independent sample T-test

SFA - Slow for age

tary motor area and links between the prefrontal cortex, basal ganglia as well as the cerebellum. $[27,28]$ The effect of methylphenidate in lessening NSS is supposed to be on the dopamine reuptake in the basal ganglia, cerebellum and cerebral cortex interconnection. [4] Therefore, it could be considered that methylphenidate acts in similar regions and may improve NSS.

\section{CONCLUSION}

Multiple abnormalities of the motor system have been identified in children with ADHD as compared to healthy controls including the persistence of overflow movements, impaired timing of motor responses and deficits in fine motor abilities. A majority of the NSS in ADHD were those of slowness of performance during repetitive tasks and miscellaneous/involuntary movements during untimed tasks. The presence of excessive overflow movements in children with ADHD appears to reflect the immaturity of the neural networks involved in inhibitory control. These NSS which are present in all patients with ADHD were noted to decrease with age.

The prevalence of NSS is much higher in children with ADHD than in controls and may be of value 
Table 4. Correlation of neurological soft sign scores in both ADHD and control group as to age $(n=28)$

\begin{tabular}{|c|c|c|c|}
\hline & Overall & ADHD & Control \\
\hline & \multicolumn{3}{|c|}{ Correlation coefficient } \\
\hline Gaits and Stations & $-0.325^{* *}$ & -0.178 & -0.397 \\
\hline Axial & -0.221 & -0.04 & -0.156 \\
\hline Right & -0.125 & 0.108 & -0.255 \\
\hline Left & -0.176 & -0.054 & -0.133 \\
\hline Overflow & $-0.371^{* *}$ & $-0.467^{* *}$ & -0.307 \\
\hline Right & $-0.371^{* *}$ & $-0.467^{* *}$ & -0.307 \\
\hline Left & $-0.371^{* *}$ & $-0.467^{* *}$ & -0.307 \\
\hline Miscellaneous/Involuntary & $-0.285^{* *}$ & -0.128 & -0.311 \\
\hline Right & $-0.306^{* *}$ & -0.158 & -0.374 \\
\hline Left & $-0.306^{* *}$ & -0.158 & -0.374 \\
\hline Timed movements & -0.081 & 0.345 & -0.244 \\
\hline Overflow & -0.284 & -0.144 & -0.384 \\
\hline Right & $-0.292^{* *}$ & -0.109 & $-0.48^{* *}$ \\
\hline Left & -0.234 & -0.103 & -0.284 \\
\hline Dysrhythmia & -0.269 & -0.042 & $-0.478^{* *}$ \\
\hline Right & -0.106 & 0.169 & -0.356 \\
\hline Left & $-0.429 * *$ & -0.352 & $-0.506^{* *}$ \\
\hline Miscellaneous/Involuntary & 0.003 & 0.041 & - \\
\hline Right & 0.008 & 0.058 & - \\
\hline Left & -0.066 & -0.083 & - \\
\hline SFA & 0.154 & $0.607^{* *}$ & 0.123 \\
\hline Right & 0.143 & $0.562^{* *}$ & 0.17 \\
\hline Left & 0.219 & $0.627^{* *}$ & 0.18 \\
\hline Total Right Overflow & $-0.336^{* *}$ & -0.241 & $-0.497^{* *}$ \\
\hline Total Left Overflow & $-0.293^{* *}$ & -0.264 & -0.3 \\
\hline Total Overall Overflow & $-0.317^{* *}$ & -0.24 & -0.404 \\
\hline PANESS Total & -0.202 & 0.099 & -0.337 \\
\hline
\end{tabular}

Correlation interpretation: [0-0.2] Very weak; (0.2-0.4] Weak; (0.4-0.6] Moderate; (0.6-0.8] Strong; (0.8-1) Very strong; 1: Perfect; (-) indirect, (+) direct

** - significant (p-value $<0.05$ )

SFA - Slow for age

in the evaluation of this disorder, to improve sensitivity in the diagnosis. An evaluation in motor function seems to be appropriate because children with ADHD and motor dysfunction in combination have a higher frequency of other problems such as obsessive-compulsive disease, depression and conduct disorder.[6, 18]

NSS was not correlated with gender, type and severity of ADHD. The majority of the NSS had no significant correlation in terms of treatment except for the dysrhythmia, which was significantly lower in patients receiving methylphenidate treatment. We, therefore, suggest that evaluation of NSS may be useful to monitor the effectiveness of pharmacological treatment among individual patients where they will serve as their own control.

\section{STRENGTHS, LIMITATIONS AND RECOMMENDATIONS}

The inclusion of healthy controls made this study more valid. The inclusion of only ADHD without other comorbidities such as learning disability and psychiatric disorders has lessened the effects of possible confounding variables. 
Table 5. Overflow movement scores between males and females in both ADHD and control group $(n=48)$

\begin{tabular}{|c|c|c|c|c|}
\hline & Total $(n=48)$ & Male $(n=32)$ & Female $(n=16)$ & $\mathrm{p}$-value \\
\hline \multicolumn{5}{|c|}{ Mean \pm SD; Median (Range) } \\
\hline Overflow & $0(0-6)$ & $0(0-6)$ & $0(0-6)$ & $0.251^{*}$ \\
\hline Right & $0(0-3)$ & $0(0-3)$ & $0(0-3)$ & $0.251^{*}$ \\
\hline Left & $0(0-3)$ & $0(0-3)$ & $0(0-3)$ & $0.251^{*}$ \\
\hline $\begin{array}{l}\text { Timed movements } \\
\text {-Overflow }\end{array}$ & $2.5(0-16)$ & $4(0-14)$ & $1(0-16)$ & $0.199 *$ \\
\hline Right & $1(0-8)$ & $2(0-6)$ & $0.5(0-8)$ & $0.302^{*}$ \\
\hline Left & $1(0-7)$ & $1.5(0-7)$ & $0(0-7)$ & $0.127^{*}$ \\
\hline Total Right Overflow & $1.5(0-10)$ & $2(0-9)$ & $0.5(0-10)$ & $0.275^{*}$ \\
\hline Total Left Overflow & $1.5(0-10)$ & $2.5(0-10)$ & $0(0-9)$ & $0.106^{*}$ \\
\hline Total Overall Overflow & $3.5(0-20)$ & $5(0-20)$ & $1(0-20)$ & $0.175^{*}$ \\
\hline
\end{tabular}

Statistical tests used: * - Wilcoxon rank-sum test

The value of the present result is limited due to a number of reasons. Firstly, there was a wide age range (6-18 years) limiting the number of children at each age level. With greater numbers of children at each age level, more discrete age-related changes might be identified, and better comparisons to performance could be made for all variables at each age level. Although our target sample size was met, only those with mild and moderate ADHD were included in the study. Larger sample size would still be recommended to increase the likelihood of measuring soft signs in severe ADHD patients. In addition, our sample was recruited from a single tertiary hospital, and therefore is not a nationally representative sample. Lastly, the normative data for PANESS was not of Filipino children, hence a possible avenue for future research on this aspect.
In an attempt to elucidate the role of NSS in ADHD patients, it is also worth exploring in future studies the effectiveness of pharmacological treatment by evaluating the motor functioning of ADHD patients at baseline and after treatment.

Additional studies on several aspects mentioned above will not only enhance our understanding of the biological bases of ADHD but will also add scientific evidence to the predictive value of NSS as indicators of the severity of functional impairment in ADHD as well as outcome predictors.

\section{Acknowledgment}

The authors wish to thank Dr. Martha B. Denckla of Kennedy Krieger Institute for sending us the necessary documents for administering the PANESS scale. 


\section{REFERENCES}

1. Polanczyk G, De Lima MS, Horta BL, Biederman J, Rohde LA. The worldwide prevalence of ADHD: a systematic review and metaregression analysis. American Journal of Psychiatry. 2007 Jun; 164(6):942-8.

2. American Psychiatric Association. Diagnostic and statistical manual of mental disorders. BMC Med. 2013;17:133-7.

3. ADHD Society of the Philippines. 2000. Available from: https://adhdsocphils.org.

4. Pasini A, D'agati E. Pathophysiology of NSS in ADHD. The World Journal of Biological Psychiatry. 2009 Jan $1 ; 10(4-2): 495-502$.

5. Dickstein DP, Garvey M, Pradella AG, Greenstein DK, Sharp WS, Castellanos FX, et al. Neurologic examination abnormalities in children with bipolar disorder or attentiondeficit/hyperactivity disorder. Biological Psychiatry. 2005 Oct 1;58(7):517-24.

6. Denckla $M B$. Revised neurological examination and subtle signs. Psychopharmacol Bull. 1985;21:773-9.

7. Gidley Larson JC, Mostofsky SH, Goldberg MC, Cutting LE, Denckla MB, Mahone EM. Effects of gender and age on motor exam in typically developing children. Developmental Neuropsychology. 2007 Jul 6;32(1):543-62.

8. Mayston M, Harrison LM, Stephens JA. A neurophysiological study of mirror movements in adults and children. Annals of Neurology: Official Journal of the American Neurological Association and the Child Neurology Society. 1999 May;45(5):583-94

9. Patankar VC, Sangle JP, Shah HR, Dave M, Kamath RM. Neurological soft signs in children with attention deficit hyperactivity disorder. Indian Journal of Psychiatry. 2012 Apr;54(2):159.

10. Pennington BF, Ozonoff S. Executive functions and developmental psychopathology. Journal of Child Psychology and Psychiatry. 1996 Jan;37(1):51-87.

11. Guy W. Physical and neurological examination for soft signs (PANESS). ECDEU Assessment Manual for Psychopharmacology. Revised. US: 383Á406. 1976.

12. Cardo E, Casanovas S, Servera M. Soft neurological signs: are they of any value in the assessment and diagnosis of attention deficit hyperactivity disorder?. Revista de Neurologia. 2008;46:S51-4.

13. Castellanos FX, Acosta MT. The neuroanatomy of attention deficit/hyperactivity disorder. Revista de Neurologia. 2004 Feb;38:S131-6.

14. Dazzan P, Morgan KD, Chitnis X, Suckling J, Morgan C, Fearon $\mathrm{P}$, et al. The structural brain correlates of neurological soft signs in healthy individuals. Cerebral Cortex. 2005 Oct 26;16(8): 1225-31.

15. Castellanos FX, Proal E. Large-scale brain systems in ADHD: beyond the prefrontal-striatal model. Trends in Cognitive Sciences. 2012 Jan 1;16(1):17-26.

16. Cao Q, Zang Y, Sun L, Sui M, Long X, Zou Q, Wang Y. Abnormal neural activity in children with attention deficit hyperactivity disorder: a resting-state functional magnetic resonance imaging study. Neuroreport. 2006 Jul 17;17(10):1033-6.

17. Barkley RA. Theories of attention-deficit/hyperactivity disorder. In: Handbook of Disruptive Behavior Disorders. 1999 (pp. 295-313). Springer, Boston, MA.

18. Mostofsky SH, Newschaffer CJ, Denckla MB. Overflow movements predict impaired response inhibition in children with ADHD. Perceptual and Motor Skills. 2003 Dec;97(suppl 3):1315-31.

19. Uslu R, Kapci EG, Oztop D. Neurological soft signs in comorbid learning and attention deficit hyperactivity disorders. Turkish Journal of Pediatrics. 2007 Jul 1;49(3):263.

20. Meyer A, Sagvolden T. Fine motor skills in South African children with symptoms of ADHD: influence of subtype, gender, age, and hand dominance. Behavioral and Brain Functions. 2006 Dec;2(1):33.

21. Pitcher TM, Piek JP, Hay DA. Fine and gross motor ability in males with ADHD. Developmental Medicine and Child Neurology. 2003 Aug;45(8):525-35.

22. Dazzan P, Morgan KD, Chitnis X, Suckling J, Morgan C, Fearon $\mathrm{P}$, et al. The structural brain correlates of neurological soft signs in healthy individuals. Cerebral Cortex. 2005 Oct 26;16(8): 1225-31.

23. Aziz A, Azza AN, El Sheikh MM, Mohsen NM, Khalil SA, Hassan AM. Neurological soft signs in a sample of Egyptian ADHD children and their clinical correlates. Middle East Current Psychiatry. 2016 Apr 1;23(2):51-5

24. Blakemore SJ, Burnett S, Dahl RE. The role of puberty in the developing adolescent brain. Human Brain Mapping. 2010 Jun;3 1 (6):926-33.

25. Lazarus JA, Todor JI. The role of attention in the regulation of associated movement in children. Developmental Medicine and Child Neurology. 1991 Jan;33(1):32-9.

26. Hadders-Algra M. Developmental coordination disorder: is clumsy motor behavior caused by a lesion of the brain at early age?. Neural Plasticity. 2003;10(1-2):39-50.

27. Gustafsson P, Svedin CG, Ericsson I, Linden C, Karlsson MK, Thernlund G. Reliability and validity of the assessment of neurological soft-signs in children with and without attention-deficit-hyperactivity disorder. Developmental Medicine \& Child Neurology. 2010 Apr;52(4):364-70.

28. Valdimarsdottir M, Hrafnsdottir AH, Magnusson P, Gudmundsson $\mathrm{O}$. The frequency of some factors in pregnancy and delivery for Icelandic children with ADHD. Laeknabladid. 2006 Sep;92(9):609-14.

29. Vitiello B, Stoff D, Atkins M, Mahoney A. Soft neurological signs and impulsivity in children. Journal of Developmental and Behavioral Pediatrics. 1990 Jun ; $11(3): 112-5$.

30. Rubia K, Noorloos J, Smith A, Gunning B, Sergeant J. Motor timing deficits in community and clinical boys with hyperactive behavior: the effect of methylphenidate on motor timing. Journal of Abnormal Child Psychology. 2003 Jun 1;31(3):301-13.

31. Pitzianti $M$, D'Agati $E$, Casarelli L, Pontis $M$, Kaunzinger I, Lange KW, et al. Neurological soft signs are associated with attentional dysfunction in children with attention deficit hyperactivity disorder. Cognitive Neuropsychiatry. 2016 Nov $1 ; 21(6): 475-93$.

32. Gidley Larson JC, Mostofsky SH, Goldberg MC, Cutting LE, Denckla MB, Mahone EM. Effects of gender and age on motor exam in typically developing children. Developmental Neuropsychology. 2007 Jul 6;32(1):543-62.

(i) Open Access This article is licensed under a Creative Commons Attribution 4.0 International License, which permits use, sharing, adaptation, distribution and reproduction in any medium or format, as long as you give appropriate credit to the original author(s) and the source, provide a link to the Creative Commons license, and indicate if changes were made. The images or other third party material in 
this article are included in the article's Creative Commons license, unless indicated otherwise in a credit line to the material. If material is not included in the article's Creative Commons license and your intended use is not permitted by statutory regulation or exceeds the permitted use, you will need to obtain permission directly from the copyright holder. To view a copy of this license, visit http://creativecommons.org/licenses/ by/4.0/. 